\title{
Epigenetic regulation of intestinal stem cells by Tet1-mediated DNA hydroxymethylation
}

\author{
Rinho Kim, Karyn L. Sheaffer, Inchan Choi, Kyoung-Jae Won, and Klaus H. Kaestner \\ Department of Genetics, Center for Molecular Studies in Digestive and Liver Diseases, Perelman School of Medicine, University \\ of Pennsylvania, Philadelphia, Pennsylvania 19104, USA
}

\begin{abstract}
Methylated cytosines are associated with gene silencing. The ten-eleven translocation (TET) hydroxylases, which oxidize methylated cytosines to 5 -hydroxymethylcytosine $(5 \mathrm{hmC})$, are essential for cytosine demethylation. Gene silencing and activation are critical for intestinal stem cell (ISC) maintenance and differentiation, but the potential role of TET hydroxylases in these processes has not yet been examined. Here, we generated genome-wide maps of the $5 \mathrm{hmC}$ mark in ISCs and their differentiated progeny. Genes with high levels of hydroxymethylation in ISCs are strongly associated with Wnt signaling and developmental processes. We found Tet1 to be the most abundantly expressed Tet gene in ISCs; therefore, we analyzed intestinal development in Tet1-deficient mice and determined that these mice are growth-retarded, exhibit partial postnatal lethality, and have significantly reduced numbers of proliferative cells in the intestinal epithelium. In addition, the Tet1-deficient intestine displays reduced organoidforming capacity. In the Tet1-deficient crypt, decreased expression of Wnt target genes such as Axin2 and Lgr5 correlates with lower $5 \mathrm{hmC}$ levels at their promoters. These data demonstrate that Tet1-mediated DNA hydroxymethylation plays a critical role in the epigenetic regulation of the Wnt pathway in intestinal stem and progenitor cells and consequently in the self-renewal of the intestinal epithelium.
\end{abstract}

[Keywords: Tet1; epigenomics; hydroxymethylation; intestinal differentiation; intestinal stem cell]

Supplemental material is available for this article.

Received July 28, 2016; revised version accepted October 21, 2016.

DNA methylation is a widespread epigenetic modification that regulates gene expression in development and cellular differentiation (Reik et al. 2001; Smith and Meissner 2013; Sheaffer et al. 2014). DNA methylation is dynamic yet tightly regulated to prevent aberrant patterns of 5-methylcytosine $(5 \mathrm{mC})$, which are common in cancer (Baylin et al. 2001; Esteller 2007). 5mC is established and maintained by DNA methyltransferase (DNMT) enzymes (Li et al. 1992; Okano et al. 1999). Recently, oxidation of $5 \mathrm{mC}$ to 5 -hydroxymethylcytosine $(5 \mathrm{hmC})$ by the teneleven translocation (TET) gene family was proposed as a novel mechanism for removal of $5 \mathrm{mC}$ (Kriaucionis and Heintz 2009; Tahiliani et al. 2009). This can occur by at least two nonmutually exclusive mechanisms. First, $5 \mathrm{hmC}$ can be further oxidized to 5 -formlyctosine $(5 \mathrm{fC})$ and then 5 -carboxylcytosine $(5 \mathrm{caC})$, again by the Tet enzymes, although at much lower efficacy than oxidation from $5 \mathrm{mC}$ to $5 \mathrm{hmC}$ (Ito et al. 2011). Both $5 \mathrm{fC}$ and $5 \mathrm{caC}$ can be glycosylated by thymine DNA glycosylase and replaced by unmodified cytosine via base excision repair (Maiti and Drohat 2011; Weber et al. 2016). Second,

Corresponding author: kaestner@mail.med.upenn.edu Article published online ahead of print. Article and publication date are online at http://www.genesdev.org/cgi/doi/10.1101/gad.288035.116. because hemimethylated $5 \mathrm{hmC}$ nucleotides are not recognized by the maintenance DNA methyltransferases following DNA replication during $S$ phase, hydroxymethylation of specific sites will lead to their targeted, passive demethylation in replicating cells. Thus, hydroxymethylation via the Tet enzymes offers an elegant pathway for even lineage-committed cells to change their DNA methylation status.

Global methylome analyses in recent years have shown that the DNA methylation status is dynamic with aging even within the same cell type (Avrahami et al. 2015). Likewise, we and others have demonstrated previously that DNA methylation at specific loci changes during differentiation of intestinal stem cells (ISCs) to enterocytes in adult mice (Kaaij et al. 2013; Sheaffer et al. 2014) and during ISC maturation in postnatal mice (Yu et al. 2015); however, how these elements are targeted for demethylation is currently unknown.

(C) 2016 Kim et al. This article is distributed exclusively by Cold Spring Harbor Laboratory Press for the first six months after the full-issue publication date (see http://genesdev.cshlp.org/site/misc/terms.xhtml). After six months, it is available under a Creative Commons License (Attribution-NonCommercial 4.0 International), as described at http:// creativecommons.org/licenses/by-nc/4.0/. 
The epithelium of the small intestine is the most rapidly self-renewing tissue in mammals, and, even in humans, the epithelium is replaced every $3-5 \mathrm{~d}$. Active Wnt signaling in the intestinal crypt is a major driving force for ISC renewal and proliferation of transit-amplifying cells. Tight regulation of Wnt signaling is critical for the intestinal epithelial homeostasis (Gregorieff and Clevers 2005). Rapidly cycling $\mathrm{Lgr}^{+}$stem cells at the bottom of the intestinal crypt give rise to transit-amplifying cells that divide up to six times further (Rao and Wang 2010) before differentiating into post-mitotic, functional cells as they exit the crypt zone and migrate up the crypt-villus axis. This process is accompanied by dramatic changes in the transcriptional program, which are mediated at least in part by epigenetic changes such as the aforementioned realignment of DNA methylation status (Kaaij et al. 2013; Sheaffer et al. 2014). In fact, in the absence of Dnmt 1 alone or both Dnmt1 and Dnmt3b, the intestinal epithelium is not viable in the postnatal period (Yu et al. 2015) or in the adult (Elliott et al. 2016), respectively. Here, we investigate to what extent targeted oxidation of $5 \mathrm{mC}$ to $5 \mathrm{hmC}$ contributes to intestinal epithelial health.

\section{Results}

The $5 \mathrm{hm} C$ mark is prominent in intestinal villus epithelial cells

To determine global $5 \mathrm{hmC}$ levels in ISCs, we performed $5 \mathrm{hmC}$ dot blot analysis of genomic DNA from isolated epithelial cells as well as brain and embryonic stem cells (ESCs) for comparison. We found that $5 \mathrm{hmC}$ levels in the gut are almost as high as those present in the brain and ESCs (Fig. 1A). Hydroxymethylation of cytosines has been suggested to play an important role in neurons due to the abundance of this mark in the brain (Hahn et al. 2013; Rudenko et al. 2013). Therefore, we hypothesized that this epigenetic mark might also be critical for the proliferation and/or differentiation of intestinal epithelial cells. We examined the distribution of global $5 \mathrm{hmC}$ compared with $5 \mathrm{mC}$ in the intestinal epithelium by immunofluorescence detection of each mark with specific antibodies. $5 \mathrm{mC}$ was present in all epithelial cells, with the highest levels in the crypt, where stem and transit-amplifying cells reside (Fig. 1B). We identified proliferating stem and transit-amplifying cells by costaining with Ki67, a marker of proliferation. Interestingly, we found that the strongest $5 \mathrm{hmC}$ signal was detected in the nuclei of differentiated villus cells, while the signal decreased in the crypt region (Fig. 1C). This finding is consistent with previous reports that $5 \mathrm{hmC}$ is depleted in proliferating cancer cells compared with post-mitotic cells (Jin et al. 2011; Lian et al. 2012).

\section{Dynamic changes of $5 \mathrm{hmC}$ distribution during intestinal} epithelial differentiation

Next, we examined dynamic genomic $5 \mathrm{hmC}$ abundance during ISC differentiation. First, we isolated
Lgr5-expressing ISCs $\left(\mathrm{Lgr5}^{+}\right)$from Lgr5-EGFP-IRESCreERT2 mice (Barker et al. 2007) by FACS and differentiated villus epithelial cells by careful scraping of the luminal side of the gut tube, respectively (Fig. 1D,E; see the detailed description in the Materials and Methods). Genomic DNA was then isolated from both cell populations. To investigate genome-wide changes of the $5 \mathrm{hmC}$ mark between $\mathrm{Lgr}^{+}$and differentiated cells, we performed hydroxymethylated DNA immunoprecipitation (hMeDIP) followed by next-generation sequencing (hMeDIP-seq) (see the Materials and Methods). Remarkably, we discovered striking differences in $5 \mathrm{hmC}$ levels in marker genes for both ISCs and mature enterocytes (Fig. 2A-C). For example, high levels of $5 \mathrm{hmC}$ were present near promoters and throughout the gene bodies of ISC marker genes such as Lgr5, Olfm4, and Msi1 and Wnt target genes such as Axin2, c-Myc, and Sox9 in $\mathrm{Lgr}^{+}$cells but were decreased dramatically after differentiation into villus epithelial cells (Fig. 2A,B). Conversely, genes expressed at high levels only in differentiated cells, such as Alpi, Sis, and Fabp1, were hydroxymethylated only in differentiated cells (Fig. 2C).

Having established that the $5 \mathrm{hmC}$ mark is dynamic for the nine genes described above, we performed a genomewide analysis of hydroxymethylation. We found an approximately eightfold increase in the total $5 \mathrm{hmC}$ signal in differentiated cells relative to $\mathrm{Lgr}^{+}$cells (Fig. 2D) and identified a total of $33,1835 \mathrm{hmC}$-enriched regions (peaks) in Lgr5 ${ }^{+}$cells and 100,707 peaks in differentiated cells using HOMER (Fig. 2E; Heinz et al. 2010). When comparing $5 \mathrm{hmC}$ peaks between the two cell populations, we identified 10,450 differentially hydroxymethylated regions (DhMRs; fivefold or more; $P<0.0001$ ) and divided them into two groups: higher $5 \mathrm{hmC}$ levels in $\mathrm{Lgr}^{+}$cells $(n=$ 2537) and higher 5hmC levels in differentiated cells $(n=$ 7903) (Fig. 2F). Interestingly, the two groups of DhMRs displayed distinct genomic distribution patterns. While Lgr5 $^{+}$DhMRs were enriched in intergenic regions, those present in differentiated cells were more likely to be located in gene bodies. We identified the closest gene for each DhMR and performed gene ontology analysis for the differentially hydroxymethylated gene sets (Fig. 2G). The genes associated with higher $5 \mathrm{hmC}$ levels in Lgr5 $5^{+}$cells were involved in "developmental process" and "cell differentiation," primary functions of stem cells. Conversely, the genes associated with higher $5 \mathrm{hmC}$ levels in differentiated cells were enriched for genes that control metabolic processes and nutrient transport, major functions of enterocytes. Thus, overall, high levels of hydroxymethylation correlated positively with the gene sets expected to be active in either $\mathrm{Lgr}^{+}$stem cells or post-mitotic differentiated villus epithelial cells.

Next, we examined the correlation between differential hydroxymethylation and differential gene expression, determined by RNA sequencing (RNA-seq) (Sheaffer et al. 2014). Genes enriched for the $5 \mathrm{hmC}$ mark in $\mathrm{Lgr}^{+}$stem cells-including ISC marker genes such as Olfm4, Lgr5, and Msi1 and Wnt target genes such as Axin2, c-Myc, and Sox9-showed higher gene expression level in Lgr5 ${ }^{+}$ stem cells than in differentiated villus epithelial cells 
A

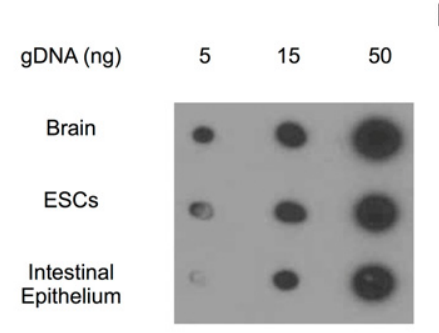

D

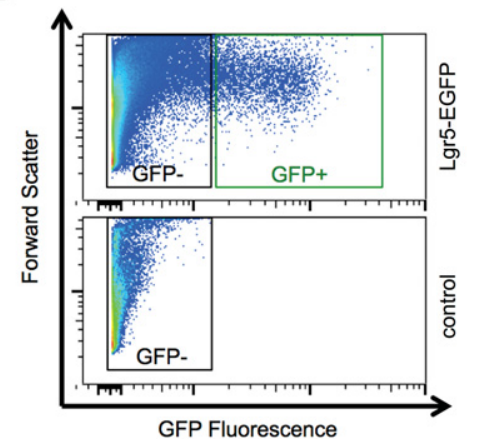

E

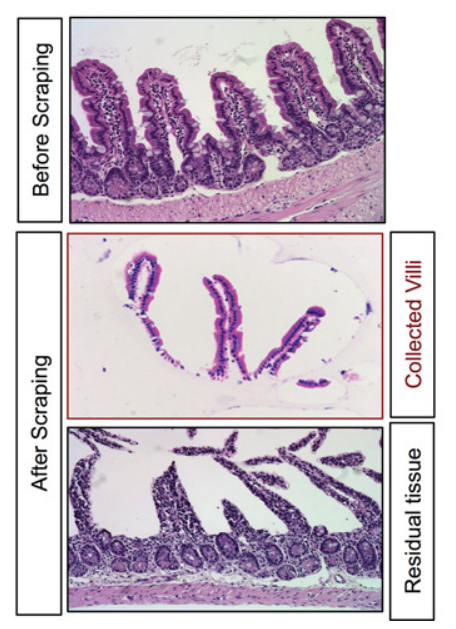

B

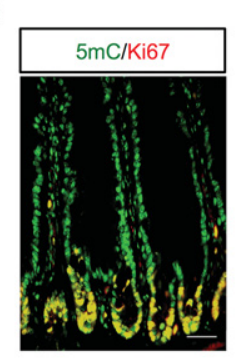

C

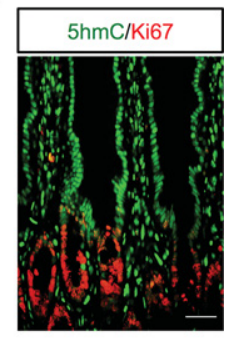

Figure 1. Differential $5 \mathrm{hmC}$ distribution in intestinal stem and differentiated cells. $(A)$ The dot blot shows global $5 \mathrm{hmC}$ levels in the mouse adult intestinal epithelium compared with the brain and ESCs. $(B$, $C)$ Immunofluorescence staining of mouse jejunum with $5 \mathrm{mC}(B), 5 \mathrm{hmC}(C)$, and $\mathrm{Ki} 67$ antibodies, as indicated. Bars, $50 \mu \mathrm{m}$. $(D)$ FACS plot to isolate Lgr5$\mathrm{EGFP}^{+}$cells and RT-qPCR validation for Lgr5 expression in $\mathrm{GFP}^{+}$cells. $(E) \mathrm{H} \& \mathrm{E}$ staining image of scraped differentiated villus cells and RT-qPCR validation for cell-specific marker genes. (Creb313) Enterocyte; (vimentin) mesenchymal cells; (hemoglobin) red blood cells.

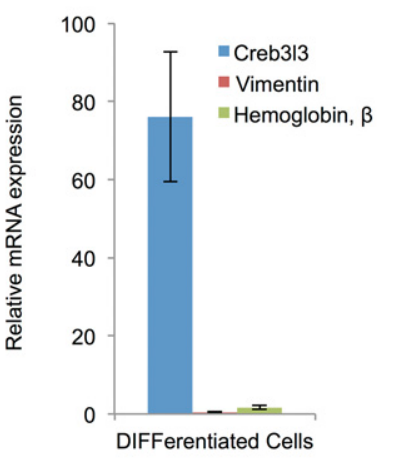

(Fig. 3A,B). Conversely, genes enriched for the $5 \mathrm{hmC}$ mark in differentiated cells, including marker genes such as Alpi, Sis, and Fabp1, exhibited increased expression in differentiated cells (Fig. 3C). Overall, gene expression changes correlated strongly with $5 \mathrm{hmC}$ level variation during ISC differentiation (Fig. 3D,E). However, we also noted some exceptions where gene expression levels were anti-correlated with $5 \mathrm{hmC}$ status. $5 \mathrm{hmC}$ has been reported to have a role in transcriptional repression in specific cases, including poised enhancers (Pastor et al. 2011; Wu et al. 2011; Choi et al. 2014).

\section{Tet1 is required for postnatal intestinal development}

Having determined that hydroxymethylation is highly dynamic during differentiation of ISCs into functional villus epithelial cells, we investigated which of the Tet enzymes is most likely controlling this process. We determined Tet 1 , Tet 2 , and Tet 3 mRNA expression levels in $\mathrm{Lgr}^{+}$stem cells and differentiated villus cells by quantitative RT-PCR (qRT-PCR) (Fig. 4A). Tet1 was expressed at much higher levels in $\mathrm{Lgr}^{+}$stem cells than in differentiated cells, while Tet2 and Tet3 showed the opposite pattern. These data suggested that Tet1 might have an essential role in $\operatorname{Lgr} 5^{+}$ISC function. Next, we phenotyped Tet1-null mutant mice (Dawlaty et al. 2011) during postnatal development, when gastrointestinal function first becomes relevant (Supplemental Table S1). Strikingly, we found that Tet1-deficient mice were growth-retarded during the early postnatal period (Fig. 4B) and showed significant postnatal lethality (Fig. 4C). In fact, viability of Tet $1^{-/-}$mice was already significantly impaired by postnatal day 3 (P3) (Fig. 4D). Tet1-deficient mice exhibited a much smaller body size (Fig. 4E), and their intestines were shorter than those of wild-type littermates (Fig. 4F). 
A A
BS in LGR5+
5 hmC in LGR5+
(RPM)
BS in DIFF
5 hmC in
DIFF (RPM)

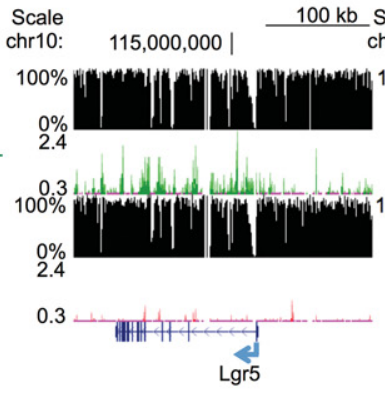
Scale
chr14: $\begin{array}{ll}20 \mathrm{~kb} & \text { Scale } \\ \text { chr5: }\end{array}$ $115,900, \frac{20 \mathrm{~kb}}{000}$

B

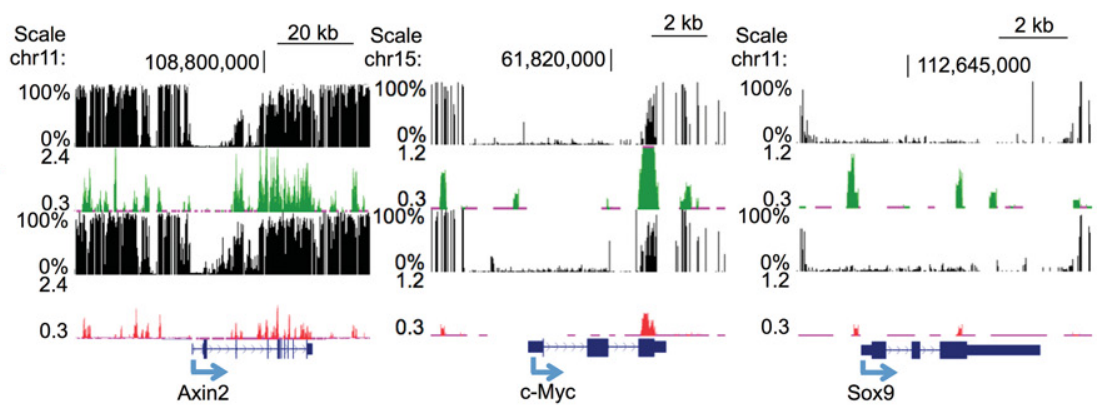

C

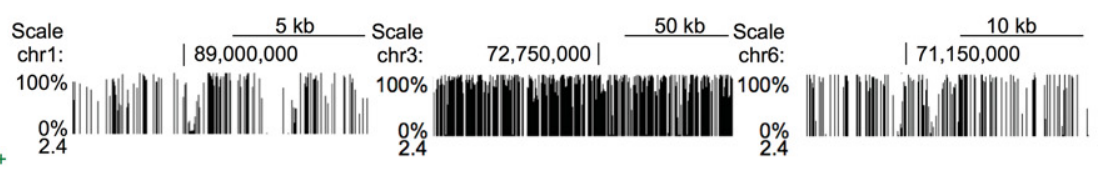

$5 \mathrm{hmC}$ in LGR5+ (RPM)

BS in DIFF

$5 \mathrm{hmC}$ in DIFF (RPM)

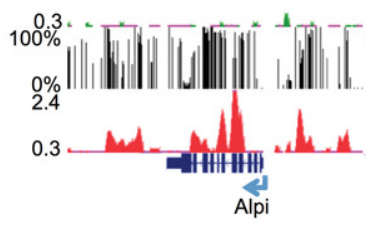

D

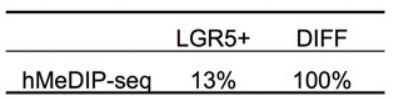

E
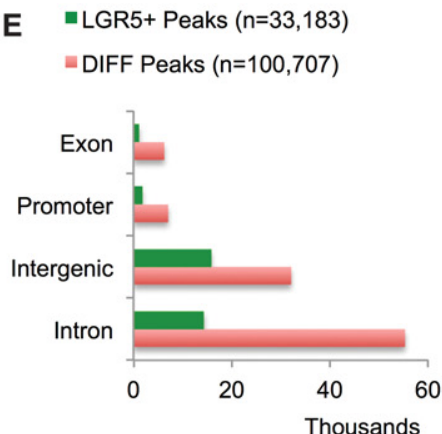

$\mathbf{F}$

DhMRs -

LGR5+ / DIFF > $5(n=2,537)$

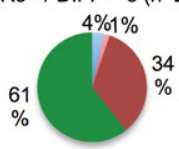

DhMRs -

DIFF / LGR5+ > $5(n=7,903)$

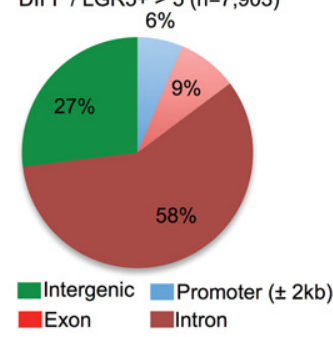

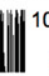
$100 \%$
$0 \%$
1.2 $0 \%$

0.3
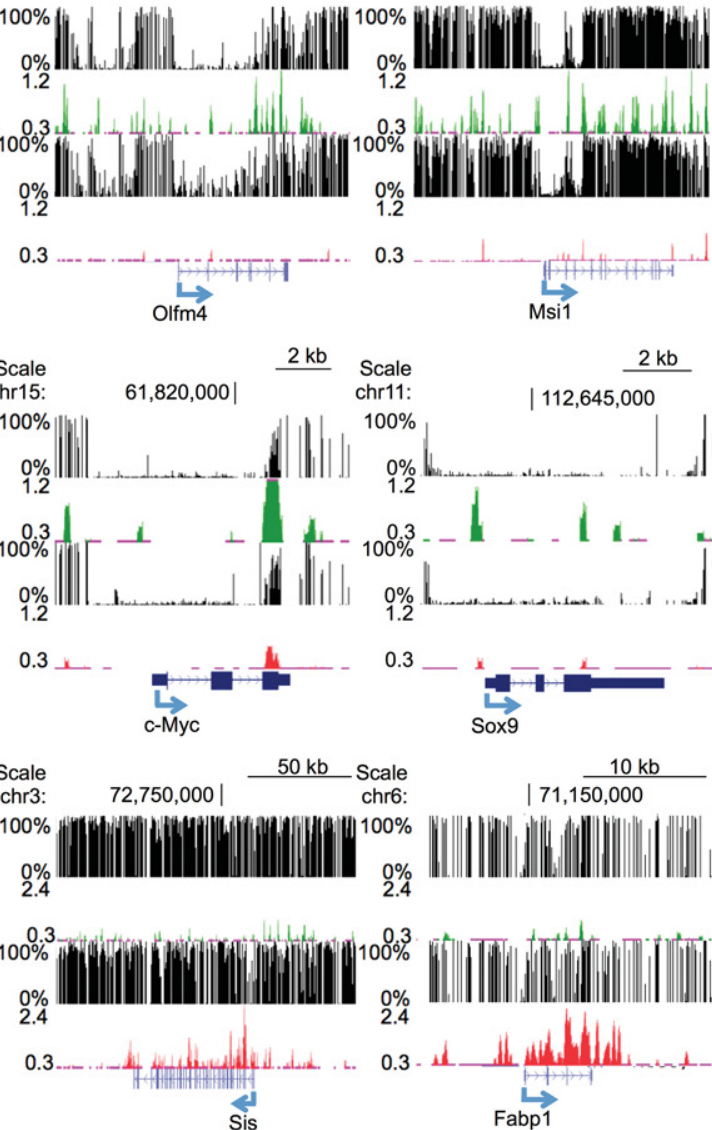

G

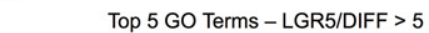

2.4

0.3 .

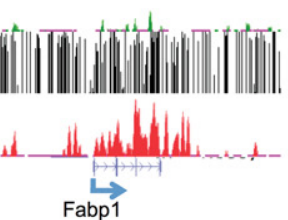

Top 5 GO Terms - LGR5/DIFF > 5

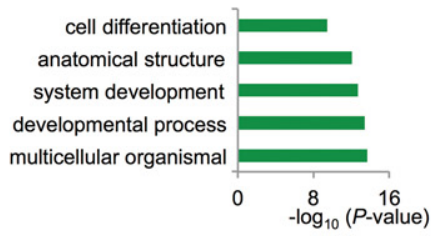

Top 5 GO Terms - DIFF/LGR5 > 5

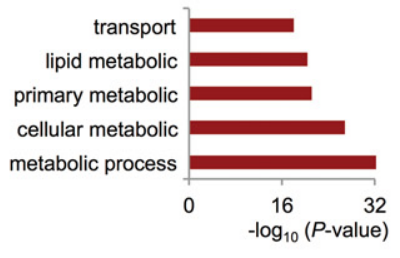

Figure 2. Genome-wide distribution of $5 \mathrm{hmC}$ and its dynamics. $(A-C)$ Screenshots of bisulfite sequencing (which measures the sum of $5 \mathrm{mC}$ and $5 \mathrm{hmC}$ ) and hMeDIP-seq (which determines $5 \mathrm{hmC}$ abundance only) at marker genes in Lgr $5^{+}$ISCs $(A)$, Wnt target genes $(B)$, and marker genes of differentiated villus cells $(C)$. Data are presented as percent methylation for the bisulfite sequencing data and as reads per million mapped reads (RPM) for the $5 \mathrm{hmC}$ data. $(D)$ The relative $5 \mathrm{hmC}$ signal of hMedIP-seq in $\mathrm{Lgr}^{+}$stem and differentiated cells. The ratio of hMeDIP/input reads numbers in differentiated epithelial cells (DIFF) was set to $100 \%$. (E) The total number of $5 \mathrm{hmC}$-enriched regions (peaks) and genomic distribution in $\mathrm{Lgr}^{+}$stem and differentiated cells (fourfold or more enrichment over local tag count). $P$-value $<0.001$. (F) Genomic distribution of differentially hydroxymethylated regions (DhMRs). (Top pie chart) regions with $5 \mathrm{hmC}$ levels that are higher in Lgr5 ${ }^{+}$stem cells than in differentiated epithelial cells (DIFF) (at least fivefold). $P$-value $<0.0001$. (Bottom pie chart) Regions with $5 \mathrm{hmC}$ levels that are higher in differentiated epithelial cells (DIFF) than in Lgr5 ${ }^{+}$stem cells (at least fivefold). $P$-value $<0.0001$. Circle size represents the total number of DhMRs in each group. $(G)$ Gene ontology search results for genes closest to DhMRs. 
A

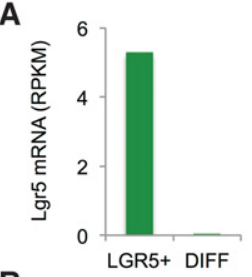

B

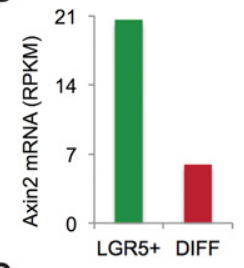

C

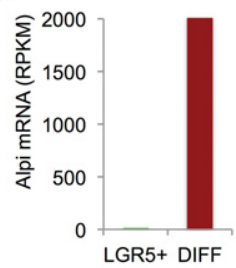

D

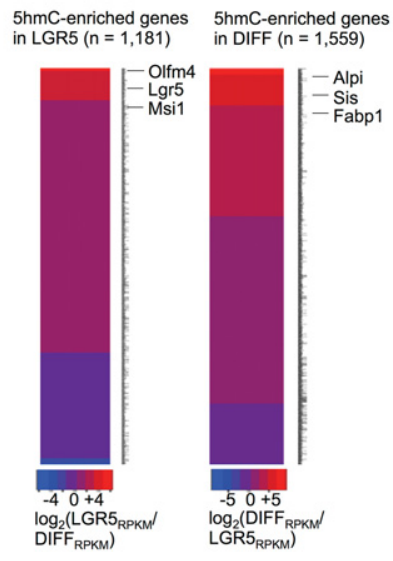

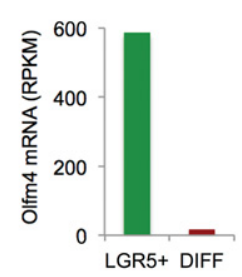
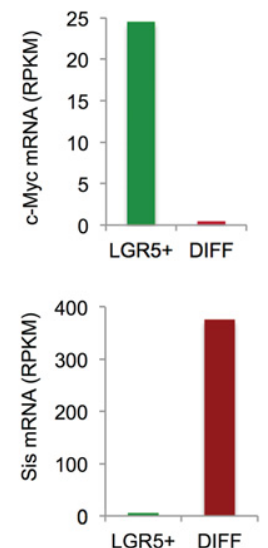

E
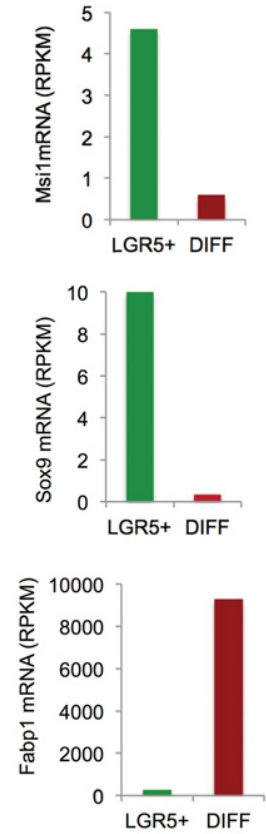

$5 \mathrm{hmC}$-enriched genes in LGR5
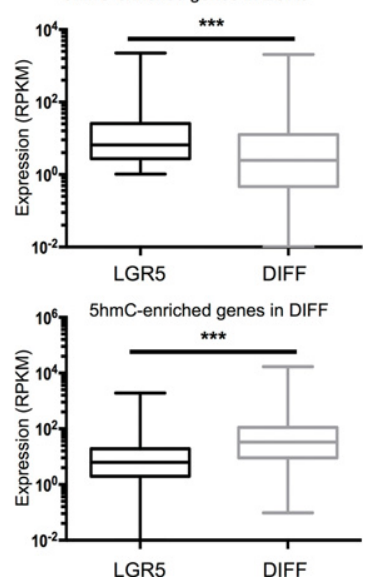

Figure 3. Positive correlation between $5 \mathrm{hmC}$-enriched gene expression levels. $(A-C)$ RNA-seq results for ISC marker genes $(A)$, Wnt target genes $(B)$, and differentiated villus cell marker genes $(C)$. RNA-seq data for both cell populations are represented as reads per kilobase per million mapped read (RPKM). (D) Heat map for differential gene expression of differentially hydroxymethylated genes $(\geq 1.5$-fold change) during intestinal epithelial differentiation. $(E)$ Box plot for differential gene expression of differentially hydroxymethylated genes in each cell population. $\left({ }^{* * *}\right) P$-value $<0.001$ by $t$-test

Wnt target genes and Lgr5 expression in the postnatal intestine are dependent on Tet 1 function

On histological examination, we found both villus length and proliferating cell number per crypt to be significantly reduced in Tet1-null mice compared with wild-type littermate controls (Fig. 5A-C). Thus, Tetl plays an important role in the maturation of the postnatal intestine. Since Wnt signaling is essential for intestinal maturation and

proliferation, we reasoned that Wnt target gene expression might be affected in Tet1-deleted mice. To examine Wnt target gene expression levels, we performed immunostaining for protein markers of Wnt pathway activation in 1-wk-old Tet1 ${ }^{-/}$- jejunum compared with wild-type littermate controls. Expression of the Wnt target genes Axin2, c-Myc, and Sox9 was clearly reduced in the mutant small intestinal crypts (Fig. 5D).

To evaluate the consequences of Tet 1 deficiency on ISC maintenance, we crossed Tet1 mutant with Lgr5-EGFPIRES-CreERT2 mice, which allowed for the easy detection of $\mathrm{Lgr5}^{+}$stem cells via expression of EGFP. We found a dramatic reduction in the frequency of Lgr5-EGFP-positive cells in the crypt of the postnatal and adult Tet1-null jejunum (Fig. 6A-C). Thus, Tet1 is required for maintaining Wnt target gene expression and normal epithelial cell morphology in the intestinal crypt.

\section{Decreased 5hmC levels at Wht target loci lead to impaired organoid formation}

Next, we investigated stem cell function in organoid culture. We found much smaller organoid size and significantly decreased organoid budding in cultures derived from the Tet1-deficient intestine (Fig. 7A-C). This suggests that the state of postnatal crypts from Tet1 $1^{-1-}$ mice is closer to fetal than adult crypts (Fordham et al. 2013; Mustata et al. 2013).

To ascertain whether the decrease in Wnt target genes and $\mathrm{Lgr} 5$ expression in $\mathrm{Tet}^{-/-}$mice was caused by altered methylation and hydroxymethylation levels, we analyzed $5 \mathrm{mC}$ and $5 \mathrm{hmC}$ levels at their loci in control and mutant mice. We found significantly increased $5 \mathrm{mC}$ levels at the Axin2 and Sox9 promoters and significantly decreased $5 \mathrm{hmC}$ levels at the promoters of Lgr5, Axin2, and Sox9 in Tet1-null mice (Fig. 7D), which correlated with the decreased expression of these genes (Figs. 5D, 6A). These findings demonstrate that Tet1-mediated hydroxymethylation is critical to allow for full activation of Wnt target genes in intestinal crypts.

\section{Discussion}

In this study, we document dynamic changes of $5 \mathrm{hmC}$ at key gene loci during ISC differentiation and report that Tet1-mediated hydroxymethylation is essential for ISC function. $5 \mathrm{hmC}$ was enriched at promoters and gene bodies of highly expressed genes in each cell type and may reverse the repressive effect of $5 \mathrm{mC}$ for gene activation. Tet 1 was expressed in ISCs but not in differentiated villus cells.

$\mathrm{Tet}^{-/-}$mice on a mixed genetic background (129Sv and C57BL/6) were reported previously to be viable but had a smaller body size and lower body weight than wild-type animals at their postnatal age (Dawlaty et al. 2011; Zhang et al. 2013). Adult Tet1 mutant mice exhibited defective self-renewal of neural progenitor (Rudenko et al. 2013; Zhang et al. 2013; Xin et al. 2015) and hematopoietic stem (Cimmino et al. 2015) cells. However, after backcrossing onto the C57BL/6 background, we observed growth retardation and decreased postnatal viability in 
A

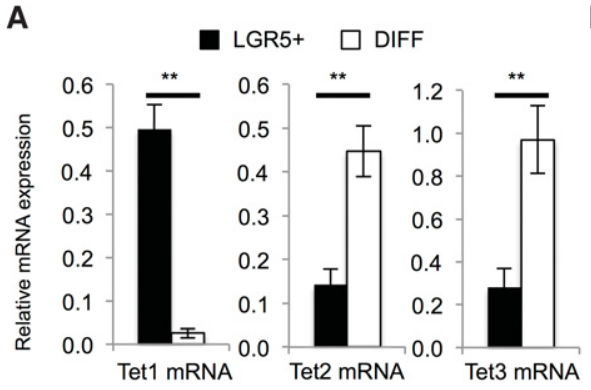

C

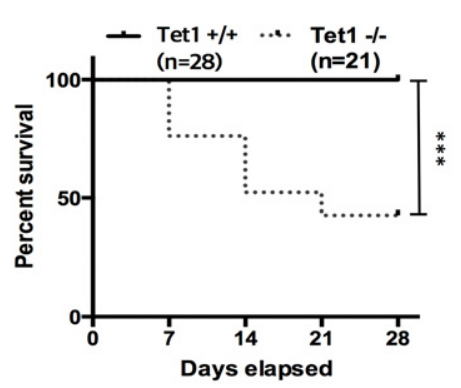

E

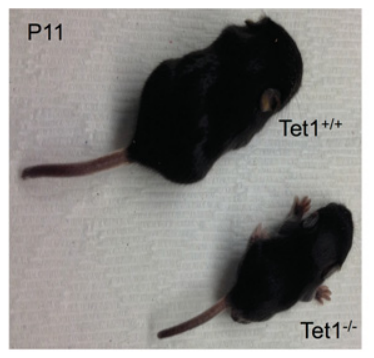

B

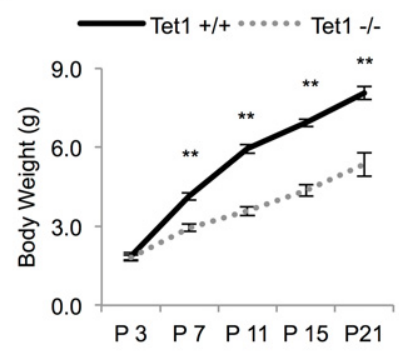

D

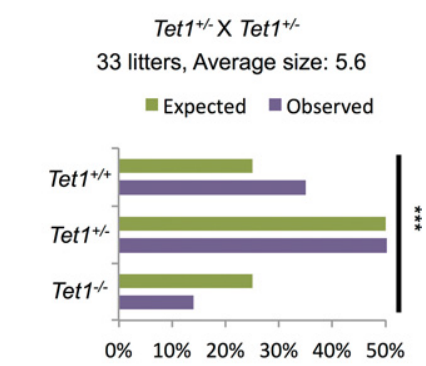

$\mathbf{F}$

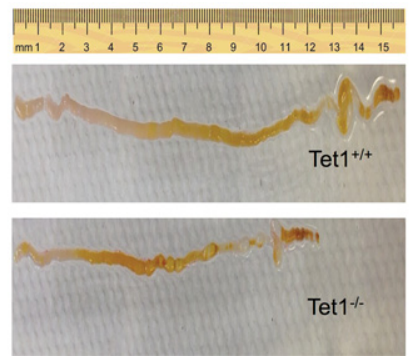

Figure 4. Postnatal developmental defects in the intestines of Tet1-null mice. (A) Relative Tet1/2/3 mRNA expression levels in Lgr $5^{+}$intestinal stem and differentiated epithelial cells of adult mice. mRNA levels were normalized to those of Tbp. (B) Tet1-null mice are growth-retarded. Weight curve during the postnatal period. $\left({ }^{* *}\right) P$-value $<0.01$ by $t$-test. $(C)$ Survival curve during the postnatal period. $\left(^{* * *}\right) P$-value $<0.001$ by a log rank (Mantel-Cox) test. $(D)$ Reduced perinatal viability of Tet1 homozygous mutants. Mice were quantified on P3. $\left(^{* * *}\right) P$-value $<0.0005, \chi^{2}$ test. (E) Representative Tet1 $1^{+/+}$and Tet1 $1^{-/-}$mice on P11. (F) Representative images of intestinal tracts of $\mathrm{Tet}^{+/+}$and $\mathrm{Tet}^{-/-}$mice at $1 \mathrm{wk}$ of age. these mice. Recently, Kang et al. (2015) also reported that Tet1-deficient C57BL/6 mice exhibit partial embryonic lethality and growth retardation; however, intestinal health was not examined in the prior study. Tet1-/mice exhibited shortened intestinal length and reduced proliferating cell number in the postnatal intestine, which is similar to the phenotype seen in mice with conditional deletion of Dnmt1 in the developing gut using Dnmt $1^{\mathrm{f} / \mathrm{f}}$; VillinCre mice (Elliott et al. 2015; Yu et al. 2015).

Lgr5 is a Wnt target gene and a stem cell marker gene in the adult intestine (Barker et al. 2007); however, a limited number of $\mathrm{Lgr}^{+}$cells are also present in the intervillus zone of the developing gut at embryonic day 16.5 (E16.5) (Kinzel et al. 2014). During intestinal maturation in the postnatal period, these Lgr5 ${ }^{+}$cells are rapidly cycling at the bottom of the crypt and clearly exhibit stem cell properties at this stage (Kim et al. 2012). These data demonstrate that Lgr5 expression in ISCs is activated around birth and maintained throughout adult life. Here we show that $5 \mathrm{hmC}$ enrichment at Wnt target loci in $\operatorname{Lgr}^{+}$ stem cells is required for full activation of gene expression, and homozygous deletion of Tet1 causes significantly decreased $5 \mathrm{hmC}$ levels at these loci, resulting in a dramatically reduced Wnt target gene expression. Importantly, loss of Tet1 also impairs budding organoid-forming capacity and thus de novo formation or expansion of stem cells in crypt culture. It was reported previously (Mustata et al. 2013) that when organoids are grown from the fetal intestine, they form spheroids instead of budding organoids and exhibit low levels of Wnt target gene expression. The organoids that we obtained from the Tet1-deleted postnatal intestine resemble these spheroids, suggesting an underdeveloped state.

In sum, our data demonstrate that Tet1-mediated conversion from $5 \mathrm{mC}$ to $5 \mathrm{hmC}$ is an important epigenetic mechanism regulating expression of Wnt target genes, including Lgr5, during postnatal intestinal maturation. The definitive role of Tet1-mediated DNA hydroxymethylation in the intestine warrants further investigation using conditional gene ablation models. Nevertheless, our results demonstrate that $5 \mathrm{hmC}$ is an essential epigenetic mark required for ISC function. DNA hydroxymethylation represents one of the switches required to activate key genes in postnatal crypt maturation and is a novel mechanism of gene regulation during ISC differentiation.

\section{Materials and methods}

Mice

All procedures involving mice were conducted under a protocol approved by the Institutional Animal Care and Use Committee 
A
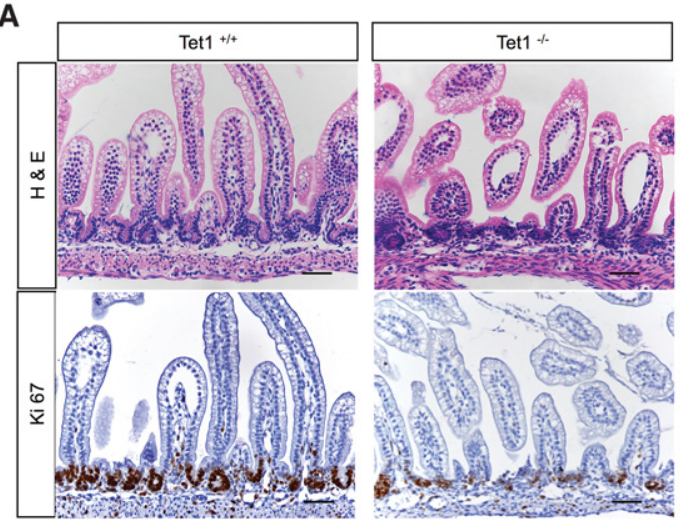

B

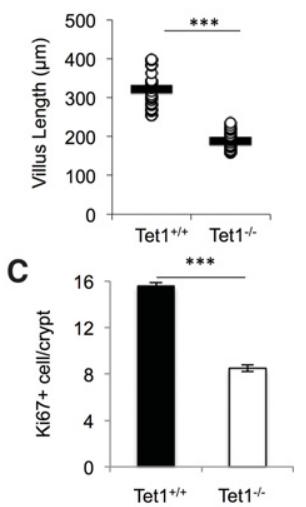

Figure 5. Decreased Wnt target gene expression in the postnatal Tet1-null intestine. (A) Histological analysis of $\mathrm{Tet1}^{+/+}$and Tet1 ${ }^{-/-}$jejunum of 1-wk-old mice. Proliferating cells are marked by immunohistochemistry for Ki67 (dark-brown signal). Bars, $50 \mu \mathrm{m}$. (B) Villus length in Tet1 ${ }^{+/+}$and Tet1 ${ }^{-/-} 1$-wk-old jejunum. $\left(^{* * *}\right) P$-value $<0.001$. (C) Ki67 $7^{+}$cell number per crypt is reduced in 1-wk-old Tet1 ${ }^{-1-}$ jejunum compared with littermate controls. $\left(^{* * *}\right) P$-value $<0.001$. (D) Immunostaining results of Wnt target gene expression, including Axin2, c-Myc, and Sox9 in P7 Tet $1^{+/+}$and Tet $^{-/-}$mice. Bars, $50 \mu \mathrm{m}$.
D

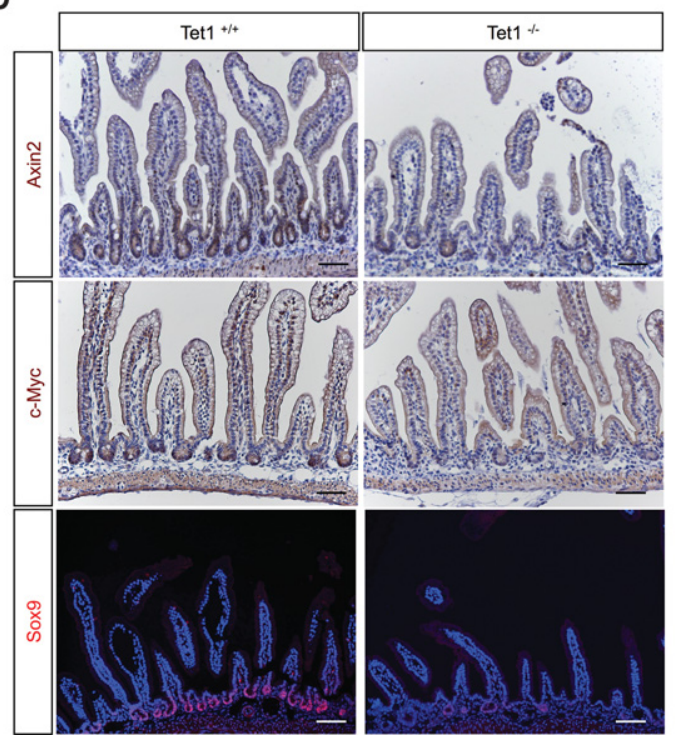

(IACUC) of the University of Pennsylvania. C57BL/6J mice (8-12 wk old) were used for all experiments unless noted otherwise. For sorting of $\mathrm{Lgr}^{+}$stem cells, we used Lgr5-EGFP-Ires-CreERT2 mice (Barker et al. 2007). Tet1 $1^{-/-}$mice (Dawlaty et al. 2011) were backcrossed to C57BL/6J mice for five generations. Eightweek-old $\mathrm{Tet}^{+/-}$mice were then intercrossed to generate Tet1 $1^{-/-}$mice. Pups were monitored for litter size and body weight gain. Survival rate calculation and statistical analyses were performed using Graphpad Prism software. Tet $1^{+/-}$mice were crossed to Lgr5-EGFP-Ires-CreERT2 mice, and $\mathrm{Tet}^{+/-}$; Lgr5-EGFP-Ires-CreERT2 mice were intercrossed to generated Tet $1^{-/} ;$Lgr5-EGFP-Ires-CreERT2 mice.

\section{Dot blot}

For the analysis of global hydroxymethylation levels, genomic DNA was isolated from mouse brains, ESCs, and small intestinal epithelia using the Allprep kit (Qiagen). dsDNAs were denatured for $10 \mathrm{~min}$ at $95^{\circ} \mathrm{C}$ and spotted onto Hybond- $\mathrm{N}^{+}$nitrocellulose membranes (GE Healthcare). The membrane was blocked with CAS-Block (Thermo Fisher Scientific) followed by overnight incubation at $4^{\circ} \mathrm{C}$ with an anti-5hmC antibody (Active Motif). Membranes were incubated with horseradish peroxidase (HRP)conjugated goat anti-mouse antibodies (GE Healthcare) for 30 min at room temperature and developed using the $\mathrm{ECL}^{+}$prime blotting detection system (GE Healthcare).

\section{Immunohistochemistry}

Dissected mouse intestinal tissues were cut open along the longitude axis, washed in cold PBS, and fixed overnight in $4 \%$ paraformaldehyde at $4^{\circ} \mathrm{C}$ before paraffin-embedding. Antigen retrieval was performed using retriever in buffer A (Electron Microscopy Sciences), and tissue sections were incubated overnight at $4^{\circ} \mathrm{C}$ with anti-5mC (Active Motif), anti-5hmC (Active Motif), antiKi67 (BD Pharmingen), anti-Axin2 (Abcam), anti-Sox9 (Millipore), anti-c-Myc (Santa Cruz Biotechnology), and anti-GFP (Aves Labs) antibodies. After incubation with secondary antibodies (Vector Laboratories) for $2 \mathrm{~h}$ at room temperature, samples were mounted in fluorescent mounting medium (Dako) or developed using the VectaStain Elite ABC kit (Vector Laboratories). Images were acquired using a Nikon Eclipse 80i fluorescence microscope and a Leica SP8 confocal microscope.

\section{Lgr5 $5^{+}$, crypt, and villus cell isolation}

Small intestines were dissected and opened longitudinally. The tissues were washed in cold PBS and scraped gently on the luminal side with a glass slide to obtain villus cells. The remaining tissue was incubated with rotation in $5 \mathrm{mM}$ EDTA/HBSS for $30 \mathrm{~min}$ at $4^{\circ} \mathrm{C}$. After EDTA incubation, the tissue was vigorously shaken for $15 \mathrm{sec}$. The first fraction was villus-rich and thus discarded. After further shaking, the supernatant enriched for 


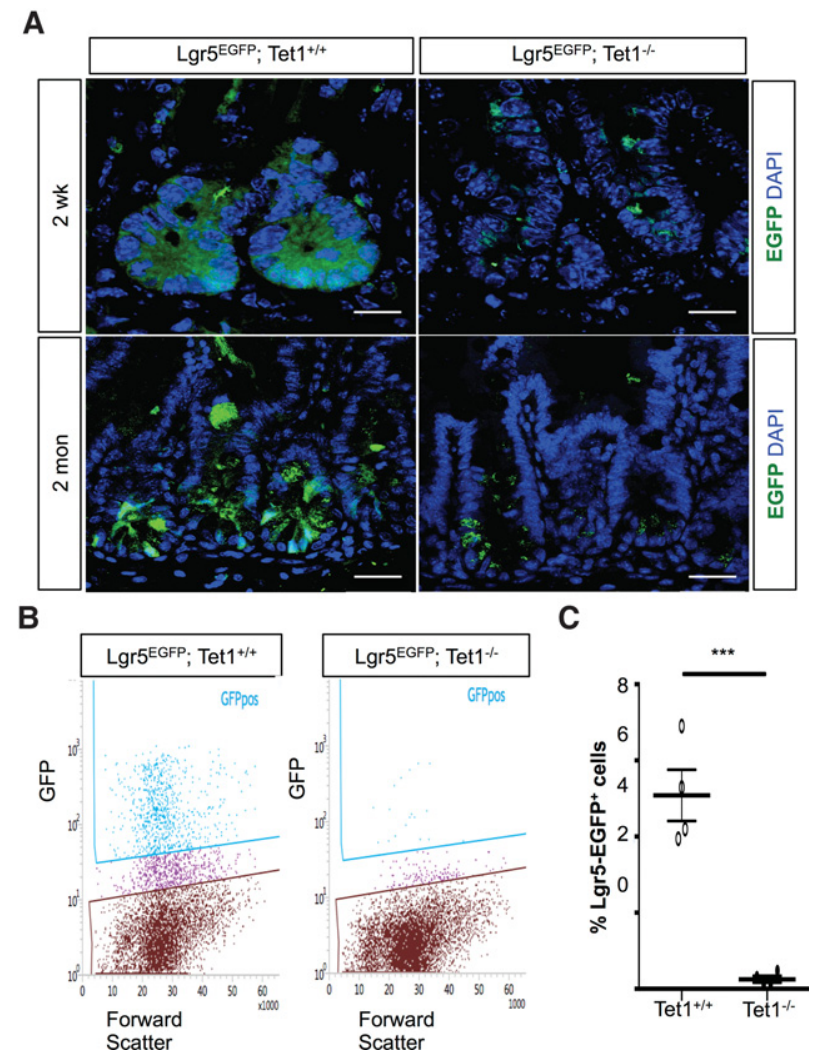

Figure 6. Reduction of Lgr5 expression in Tet1-null mouse intestines. (A) Decreased Lgr5-EGFP expression levels in 2-wk-old and 2-mo-old Tet1-null jejunum as detected by immunofluorescence staining of GFP (green). Bars, $20 \mu \mathrm{m}$. (B) FACS analysis demonstrates loss of Lgr5-EGFP ${ }^{+}$cells in 2-mo-old Tet1 $1^{-/-}$mice. $(C)$ Quantification of Lgr5-EGFP ${ }^{+}$cell number in 2-mo-old Tet1 ${ }^{+/+}$ and Tet $1^{-1-}$ mice. $\left(^{* * *}\right) P$-value $<0.001 . n=4$.

intestinal crypts was passed through a $70-\mu \mathrm{m}$ cell strainer to remove residual villus material and was centrifuged at $600 \mathrm{rpm}$ for $2 \mathrm{~min}$ to collect crypts. For $\mathrm{Lgr5}^{+}$cell sorting, isolated crypts were dissociated with TrypLe express (Thermo Fisher Scientific) for $20 \mathrm{~min}$ at $37^{\circ} \mathrm{C}$ and shaken every $5 \mathrm{~min}$ to prevent cell clumping. Dissociated cells were passed through a $40-\mu \mathrm{m}$ cell strainer and washed with Hank's balanced salt solution (HBSS). $\mathrm{GFP}^{+}$cells were separated on a FACS Diva (BD Bioscience).

\section{DNA (hydroxyl)methylation analysis}

Genomic DNA was isolated from sorted Lgr5 ${ }^{+}$, crypt, and villus cells using the AllPrep kit (Qiagen) and sonicated to an average size of 150-300 base pairs (bp) (Covaris). DNA fragments were denatured for $10 \mathrm{~min}$ at $95^{\circ} \mathrm{C}$ and immunoprecipitated using $2 \mu \mathrm{L}$ of anti-5mC (Active Motif) or anti-5hmC (Active Motif) antibody and $10 \mu \mathrm{L}$ of Protein G beads (Thermo Fisher Scientific) in immunoprecipitation buffer (10 mM sodium phosphate at $\mathrm{pH} 7.0,140$ $\mathrm{mM} \mathrm{NaCl}, 0.05 \%$ Triton X-100). For Me/hMeDIP-qPCR, hydroxymethylated DNA and input DNA were quantified on an Mx3005P qPCR system (Applied Biosystems) using the Brilliant II SYBR Green qPCR master mix (Agilent). qPCR primer sequenc- es are in Supplemental Table S3. For hMeDIP-seq, DNA fragments were ligated with Illumina adaptors using the NEBNext DNA library preparation master mix set (New England Biolabs). Following adaptor ligation, DNA fragments were denatured and immunoprecipitated using an anti-5hmC antibody (Active Motif). Hydroxymethylated DNA was amplified with adapter-specific primers (12 cycles). Amplified fragments ranging from 150 to 200 bp were size-selected followed by sequencing on a HiSeq2000 (Illumina).

\section{Mapping of sequencing data and bioinformatics}

Reads were aligned to the mouse reference genome (NCBI build 37, mm9) using Bowtie (Langmead et al. 2009). Only unique reads were used for peak calling and annotation by HOMER (Heinz et al. 2010). BedGraph files were generated and viewed on the University of California at Santa Cruz Genome Browser. DhMRs were determined by comparing $5 \mathrm{hmC}$ peak levels in one sample with the other in each direction (fold change cutoff $=5$; $P$-value cutoff $\left.=1.00 \times 10^{-4}\right)$. Gene ontology analysis was performed with DAVID (Huang et al. 2009). 5hmC-enriched genes in each cell population were determined by comparing the average of normalized $5 \mathrm{hmC}$ tag numbers in each gene promoter and body region (fold change cutoff $=1.5$ ).

\section{RNA isolation, $q P C R$, and $m R N A$-seq analysis}

Total RNA and complementary DNA (cDNA) were prepared using the AllPrep kit (Qiagen,) and SuperScript first strand synthesis system (Thermo Fisher Scientific). qRT-PCR reactions were performed on an Mx3005P qPCR system (Applied Biosystems) using Brilliant II SYBR Green qPCR master mix (Agilent). Relative expression levels were determined using comparative $\mathrm{Ct}$ values after normalizing to Tbp. qPCR primer sequences are in Supplemental Table S2. The RNA-seq method was detailed previously (Sheaffer et al. 2014).

\section{Intestine organoid culture}

Isolated intestinal crypts were resuspended in Matrigel (Corning) and covered with standard EGF/Noggin/R-spondin medium (Sato et al. 2009). Culture medium was changed every other day.

\section{Data access}

hMeDIP-seq data generated in this study have been deposited in ArrayExpress under accession number E-MTAB-5202.

\section{Acknowledgments}

We are grateful to Dr. Chris Lengner and Dr. Maria Golson for helpful discussions and comments on the manuscript, and Tia Bernard for maintenance of the mouse colony. We thank the morphology core of the Penn Center for Molecular Studies in Digestive and Kidney Disease (P30-DK050306) for reagents and technical assistance, and the Functional Genomics Core of the Penn Diabetes Research Center (P30-DK019525) for performing sequencing and analysis. This work was funded by R37DK053839 to K.H.K. R.K. performed experiments and wrote the manuscript draft. K.L.S., I.C., and K.-J.W. contributed data and analyses. K.H.K. conceived and directed the study and edited the manuscript. 
A

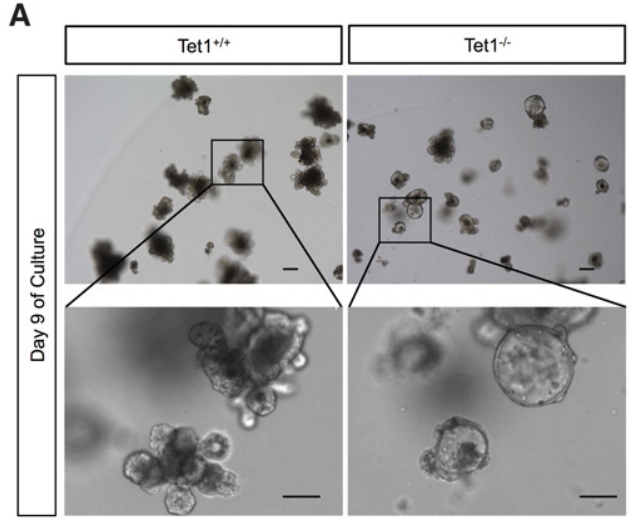

D
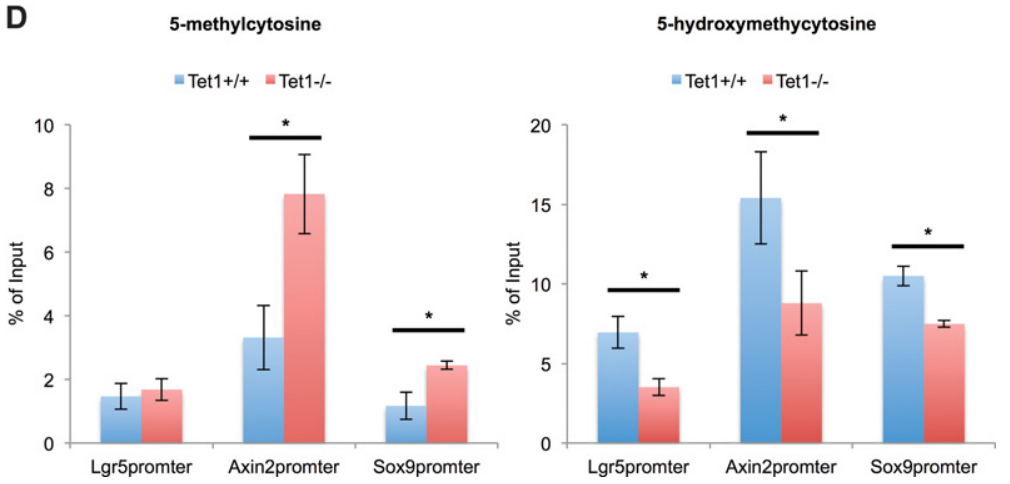

Figure 7. Budding organoid-forming potential is reduced in the absence of Tet1. (A) Images of intestinal organoid formation from 2-wk-old Tet $1^{+/+}$and Tet $1^{-/-}$ jejunal crypts. Bars, $10 \mu \mathrm{m} .(B)$ Quantification of intestinal organoid volume after $9 \mathrm{~d}$ of culture. $\left({ }^{* *}\right) P$ value $<0.01 . n=3$. $(C)$ Ratio of budding organoids over total organoids and spheroids. $\left(^{*}\right) P$-value $<0.05$. $n=3$. (D) Differential $5 \mathrm{mC}$ and $5 \mathrm{hmC}$ levels at the promoters of Lgr5, Axin2, and Sox9 in 2-wk-old Tet $1^{+/+}$and Tet $1^{-/-}$crypts. $\left({ }^{*}\right) P$-value $<0.05 . n=3$.

\section{References}

Avrahami D, Li C, Zhang J, Schug J, Avrahami R, Rao S, Stadler MB, Burger L, Schübeler D, Glaser B, et al. 2015. Aging-dependent demethylation of regulatory elements correlates with chromatin state and improved $\beta$ cell function. Cell Metab 22: 619-632.

Barker N, van Es JH, Kuipers J, Kujala P, van den Born M, Cozijnsen M, Haegebarth A, Korving J, Begthel H, Peters PJ, et al. 2007. Identification of stem cells in small intestine and colon by marker gene Lgr5. Nature 449: 1003-1007.

Baylin SB, Esteller M, Rountree MR, Bachman KE, Schuebel K, Herman JG. 2001. Aberrant patterns of DNA methylation, chromatin formation and gene expression in cancer. Hum Mol Genet 10: 687-692.

Choi I, Kim R, Lim H-WW, Kaestner KH, Won K-JJ. 2014. 5hydroxymethylcytosine represses the activity of enhancers in embryonic stem cells: a new epigenetic signature for gene regulation. BMC Genomics 15: 670.

Cimmino L, Dawlaty MM, Ndiaye-Lobry D, Yap Y, Bakogianni S, Yu Y, Bhattacharyya S, Shaknovich R, Geng H, Lobry C, et al. 2015. TET1 is a tumor suppressor of hematopoietic malignancy. Nat Immunol 16: 653-662.

Dawlaty MM, Ganz K, Powell BE, Hu Y-CC, Markoulaki S, Cheng AW, Gao Q, Kim J, Choi S-WW, Page DC, et al. 2011. Tet 1 is dispensable for maintaining pluripotency and its loss is compatible with embryonic and postnatal development. Cell Stem Cell 9: 166-175.

Elliott EN, Sheaffer KL, Schug J, Stappenbeck TS, Kaestner KH. 2015. Dnmt1 is essential to maintain progenitors in the perinatal intestinal epithelium. Development 142: 2163-2172.
Elliott EN, Sheaffer KL, Kaestner KH. 2016. The 'de novo' DNA methyltransferase Dnmt3b compensates the Dnmt1-deficient intestinal epithelium. Elife 5.

Esteller M. 2007. Cancer epigenomics: DNA methylomes and histone-modification maps. Nat Rev Genet 8: 286-298.

Fordham RP, Yui S, Hannan N, Soendergaard C, Madgwick A, Schweiger PJ, Nielsen OH, Vallier L, Pedersen RA, Nakamura $\mathrm{T}$, et al. 2013. Transplantation of expanded fetal intestinal progenitors contributes to colon regeneration after injury. Cell Stem Cell 13: 734-744.

Gregorieff A, Clevers H. 2005. Wnt signaling in the intestinal epithelium: from endoderm to cancer. Genes Dev 19: 877-890.

Hahn MA, Qiu R, Wu X, Li AX, Zhang H, Wang J, Jui J, Jin S-GG, Jiang Y, Pfeifer GP, et al. 2013. Dynamics of 5-hydroxymethylcytosine and chromatin marks in Mammalian neurogenesis. Cell Rep 3: 291-300.

Heinz S, Benner C, Spann N, Bertolino E, Lin YC, Laslo P, Cheng JX, Murre C, Singh H, Glass CK. 2010. Simple combinations of lineage-determining transcription factors prime cis-regulatory elements required for macrophage and B cell identities. Mol Cell 38: 576-589.

Huang DW, Sherman BT, Lempicki RA. 2009. Systematic and integrative analysis of large gene lists using DAVID bioinformatics resources. Nat Protoc 4: 44-57.

Ito S, Shen L, Dai Q, Wu SC, Collins LB, Swenberg JA, He C, Zhang Y. 2011. Tet proteins can convert 5-methylcytosine to 5-formylcytosine and 5-carboxylcytosine. Science 333: 1300-1303.

Jin S-GG, Jiang Y, Qiu R, Rauch TA, Wang Y, Schackert G, Krex D, Lu Q, Pfeifer GP. 2011. 5-Hydroxymethylcytosine is strongly depleted in human cancers but its levels do not correlate with IDH1 mutations. Cancer Res 71: 7360-7365. 
Kaaij LT, van de Wetering M, Fang F, Decato B, Molaro A, van de Werken HJ, van Es JH, Schuijers J, de Wit E, de Laat W, et al. 2013. DNA methylation dynamics during intestinal stem cell differentiation reveals enhancers driving gene expression in the villus. Genome Biol 14: R50.

Kang I, Lienhard M, Pastor WA, Chawla A, Novotny M, Tsagaratou A, Lasken RS, Thompson EC, Surani MA, Koralov SB, et al. 2015. Simultaneous deletion of the methylcytosine oxidases Tet 1 and Tet 3 increases transcriptome variability in early embryogenesis. Proc Natl Acad Sci 112: 45.

Kim T-HH, Escudero S, Shivdasani RA. 2012. Intact function of Lgr5 receptor-expressing intestinal stem cells in the absence of Paneth cells. Proc Natl Acad Sci 109: 3932-3937.

Kinzel B, Pikiolek M, Orsini V, Sprunger J, Isken A, Zietzling S, Desplanches M, Dubost V, Breustedt D, Valdez R, et al. 2014. Functional roles of Lgr4 and Lgr5 in embryonic gut, kidney and skin development in mice. Dev Biol 390: 181-190.

Kriaucionis S, Heintz N. 2009. The nuclear DNA base 5-hydroxymethylcytosine is present in Purkinje neurons and the brain. Science 324: 929-930.

Langmead B, Trapnell C, Pop M, Salzberg SL. 2009. Ultrafast and memory-efficient alignment of short DNA sequences to the human genome. Genome Biol 10: R25.

Li E, Bestor TH, Jaenisch R. 1992. Targeted mutation of the DNA methyltransferase gene results in embryonic lethality. Cell 69: 915-926.

Lian CG, Xu Y, Ceol C, Wu F, Larson A, Dresser K, Xu W, Tan L, $\mathrm{Hu} \mathrm{Y}, \mathrm{Zhan} \mathrm{Q}$, et al. 2012. Loss of 5-hydroxymethylcytosine is an epigenetic hallmark of melanoma. Cell 150: 1135-1146.

Maiti A, Drohat AC. 2011. Thymine DNA glycosylase can rapidly excise 5-formylcytosine and 5-carboxylcytosine potential implications for active demethylation of CpG sites. I Biol Chem 286: 35334-35338.

Mustata RC, Vasile G, Fernandez-Vallone V, Strollo S, Lefort A, Libert F, Monteyne D, Pérez-Morga D, Vassart G, Garcia MI. 2013. Identification of Lgr5-independent spheroid-generating progenitors of the mouse fetal intestinal epithelium. Cell Rep 5: 421-432.

Okano M, Bell DW, Haber DA, Li E. 1999. DNA methyltransferases Dnmt3a and Dnmt3b are essential for de novo methylation and mammalian development. Cell 99: 247-257.

Pastor WA, Pape UJ, Huang Y, Henderson HR, Lister R, Ko M, McLoughlin EM, Brudno Y, Mahapatra S, Kapranov P, et al. 2011. Genome-wide mapping of 5-hydroxymethylcytosine in embryonic stem cells. Nature 473: 394-397.
Rao JN, Wang J-YY. 2010. Regulation of gastrointestinal mucosal growth. Morgan \& Claypool Publishers. San Rafael, CA.

Reik W, Dean W, Walter J. 2001. Epigenetic reprogramming in mammalian development. Science 293: 1089-1093.

Rudenko A, Dawlaty MM, Seo J, Cheng AW, Meng J, Le T, Faull KF, Jaenisch R, Tsai L-HH. 2013. Tet1 is critical for neuronal activity-regulated gene expression and memory extinction. Neuron 79: 1109-1122.

Sato T, Vries RG, Snippert HI, van de Wetering M, Barker N, Stange DE, van Es JH, Abo A, Kujala P, Peters PJ, et al. 2009. Single Lgr5 stem cells build crypt-villus structures in vitro without a mesenchymal niche. Nature 459: 262-265.

Sheaffer KL, Kim R, Aoki R, Elliott EN, Schug J, Burger L, Schübeler D, Kaestner KH. 2014. DNA methylation is required for the control of stem cell differentiation in the small intestine. Genes Dev 28: 652-664.

Smith ZD, Meissner A. 2013. DNA methylation: roles in mammalian development. Nat Rev Genet 14: 204-220.

Tahiliani M, Koh KP, Shen Y, Pastor WA, Bandukwala H, Brudno Y, Agarwal S, Iyer LM, Liu DR, Aravind L, et al. 2009. Conversion of 5-methylcytosine to 5-hydroxymethylcytosine in mammalian DNA by MLL partner TET1. Science 324: 930-935.

Weber AR, Krawczyk C, Robertson AB, Kuśnierczyk A, Vågbø CB, Schuermann D, Klungland A, Schär P. 2016. Biochemical reconstitution of TET1-TDG-BER-dependent active DNA demethylation reveals a highly coordinated mechanism. Nat Commun 7: 10806.

Wu H, D'Alessio AC, Ito S, Wang Z, Cui K, Zhao K, Sun YE, Zhang Y. 2011. Genome-wide analysis of 5-hydroxymethylcytosine distribution reveals its dual function in transcriptional regulation in mouse embryonic stem cells. Genes Dev 25: 679-684.

Xin Y-JJ, Yuan B, Yu B, Wang Y-QQ, Wu J-JJ, Zhou W-HH, Qiu Z. 2015. Tet1-mediated DNA demethylation regulates neuronal cell death induced by oxidative stress. Sci Rep 5: 7645.

Yu D-HH, Gadkari M, Zhou Q, Yu S, Gao N, Guan Y, Schady D, Roshan TN, Chen M-HH, Laritsky E, et al. 2015. Postnatal epigenetic regulation of intestinal stem cells requires DNA methylation and is guided by the microbiome. Genome Biol 16: 211.

Zhang R-RR, Cui Q-YY, Murai K, Lim YC, Smith ZD, Jin S, Ye P, Rosa L, Lee YK, Wu H-PP, et al. 2013. Tet1 regulates adult hippocampal neurogenesis and cognition. Cell Stem Cell 13: $237-245$. 


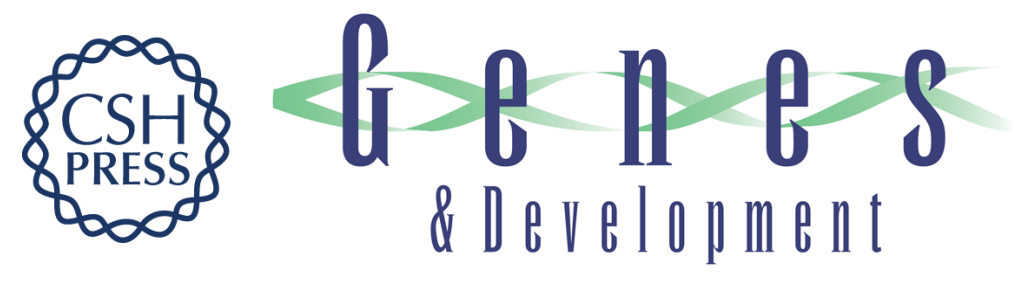

\section{Epigenetic regulation of intestinal stem cells by Tet1-mediated DNA hydroxymethylation}

Rinho Kim, Karyn L. Sheaffer, Inchan Choi, et al.

Genes Dev. 2016, 30: originally published online November 17, 2016

Access the most recent version at doi:10.1101/gad.288035.116

\section{Supplemental http://genesdev.cshlp.org/content/suppl/2016/11/17/gad.288035.116.DC1 Material}

References This article cites 38 articles, 11 of which can be accessed free at: http://genesdev.cshlp.org/content/30/21/2433.full.html\#ref-list-1

Creative This article is distributed exclusively by Cold Spring Harbor Laboratory Press for the first Commons six months after the full-issue publication date (see

License http://genesdev.cshlp.org/site/misc/terms.xhtml). After six months, it is available under a Creative Commons License (Attribution-NonCommercial 4.0 International), as described at http://creativecommons.org/licenses/by-nc/4.0/.

Email Alerting Receive free email alerts when new articles cite this article - sign up in the box at the top Service right corner of the article or click here.

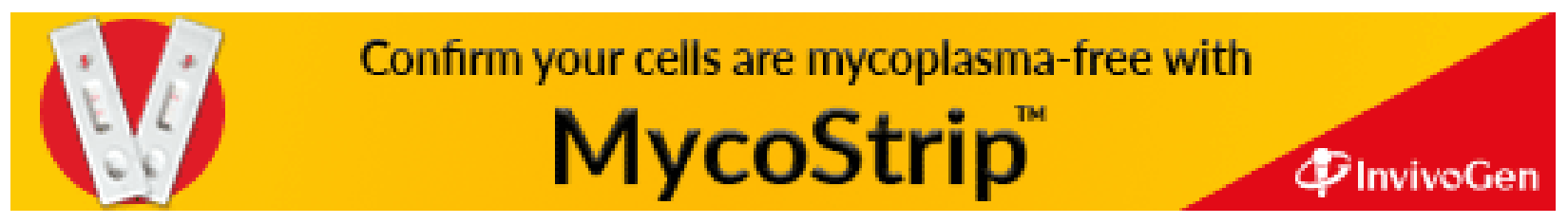

